\title{
Feedback from Usability Evaluation to User Interface Design: Are Usability Reports Any Good?
}

\author{
Christian M. Nielsen ${ }^{1}$, Michael Overgaard ${ }^{2}$, Michael B. Pedersen ${ }^{2}$, and Jan Stage ${ }^{1}$ \\ ${ }^{1}$ Aalborg University, Department of Computer Science, \\ Fredrik Bajers Vej 7, DK-9220 Aalborg East, Denmark \\ \{monrad, jans\}@es.aau.dk \\ ${ }^{2}$ ETI A/S, \\ Bouet Moellevej 3-5, DK-9400 Nr. Sundby, Denmark \\ michael@netmo.dk, mbp@least.dk
}

\begin{abstract}
This paper reports from an exploratory study of means for providing feedback from a usability evaluation to the user interface designers. In this study, we conducted a usability evaluation of a mobile system that is used by craftsmen to register use of time and materials. The results of this evaluation were presented to the designers in different forms. First, the designers were presented with a traditional usability report. Second, we facilitated a dialogue where the results of the evaluation were discussed. During this process, we collected opinions from the designers on the main strengths and weaknesses of the system. The findings indicate that detailed descriptions of problems and log descriptions of the user's interaction with the system and of system interaction are useful for the designers when trying to understand the usability problems that the users have encountered.
\end{abstract}

\section{Introduction}

The purpose of a usability evaluation is to assess the quality of a user interface design and establish a basis for improving it. Usability evaluations and the related activities can help designers make better decisions, and thereby allow them to do their jobs more effectively [25].

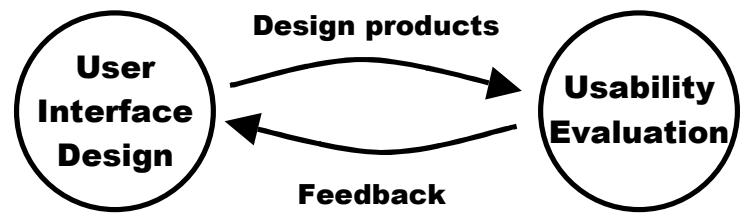

Fig. 1. The interplay between user interface design and usability evaluation.

The interplay between user interface design and usability evaluation activities can in a simplified manner be illustrated as in Fig. 1. The design process produces a vari- 
ety of user interface designs. Usability evaluations are conducted on some of these products, and the results are subsequently fed back into the design process.

There are many different design products that can be examined in a usability evaluation. The most apparent product is the system itself. A usability evaluation based on the final system has been denoted as a validation test [28]. The most typical product that is used for a usability evaluation is a less complete but still operational prototype of the system. This has been denoted as an assessment test [28]. It has also been suggested to use very early design sketches, e.g. paper prototypes. This form of evaluation has been denoted as an exploratory test [28].

The feedback also takes a variety of forms. By far the most typical one is a traditional written report that presents a number of usability problems. Other forms have also been explored, such as meetings with designers, edited videos, re-design proposals, etc.

In this paper we study and discuss different forms of feedback from usability evaluation to user interface design. The main focus is on the qualities of a written report, but we also deal with other means for feedback. In the following section 2, we provide a survey of previous work on the means for providing feedback. In section 3 , we describe the experiment that we have conducted in order to examine the relevance of some forms of feedback. Section 4 presents the results of this experiment. In section 5 , the results are discussed in a broader context, and section 6 concludes the paper.

\section{Related Work}

The interplay that is illustrated in Fig. 1 involves two different roles: designer and evaluator. The literature on usability engineering includes a significant body of research that deals with the relation between the designers and the evaluators on an organizational level. We have identified three different ways of structuring the relation between designers and evaluators: (1) the evaluators are integrated in the development teams and conduct evaluations as part of the work in the team, (2) the evaluators form a separate organizational unit within the development organization and they conduct evaluations as a service to development teams, and (3) the evaluators are employed by a different organization and evaluations are outsourced to this organization from the development organization.

The integration approach (1) focuses on the organizational and interpersonal aspects of usability evaluation in a software development organization. Some describe how usability engineers are best adopted and introduced into existing development groups $[15,16]$. There have also been efforts to simplify the integration problem by training designers to conduct usability evaluations. Others attend to how organizational focus, on all levels of the organisation, can be directed towards usability [8, 25]. When the organizational setup is based on usability specialists being a part of the development team, there is little need for formalized forms of feedback, because results are taken directly into the development process by the evaluators [2]. The only need for feedback is save the results for later reference.

The separate unit approach (2) has been discussed by many authors. Rohn [27] portrays a usability engineering group inside SunSoft, which provide support and per- 
forms usability evaluations across the organization. Several authors describe the use of specialized usability groups/departments employing usability professionals $[4,10$, $14,19,23,29,32]$. With this organizational form, there is a manifest need for some form of formalized feedback.

The outsourcing approach (3) has had less attention. One of the contributions states that an alternative to being either centralized or distributed is third-party vendors providing services to other companies [6]. There are also documented examples of projects where the evaluation has been outsourced [20]. This approach requires even more formalized feedback compared to the second approach.

For several years, the primary focus has been on the second approach (separate unit). A study of software organizations emphasized a tendency toward separating designers and usability specialists in distinct organizational units. It is also reflected in the amount of literature that deals with this approach. More recently, there has been an increasing interest in the third approach (outsourcing) [6, 20].

The literature on strengths and weaknesses of different forms of feedback is very limited. A reason for this is that most of the research that report on design and evaluation of specific systems employ the first approach (integration). A review of papers that present usability evaluations of mobile systems showed that in all of the 58 papers examined, the designers and the evaluators were the same individuals [21]. Thus in research experiments it is often the designers themselves, who perform the usability evaluation. This approach has both advantages and disadvantages concerning the outcome of a usability evaluation. The advantage is that the evaluators are familiar with the application domain as well as the functionality and design of the system [12]. On the other hand, the lack of independence between the designer and the evaluator might result in a less objective evaluation since the designer is biased towards the system [1].

When the second (separate unit) or third (outsourcing) approach is employed, there is a need for formalized feedback. In that case, most of the literature seems to take for granted that this feedback must be a written report. In Dumas \& Redish [7], Rubin [28] and Molich [17] usability reports are suggested as a mean for communicating the results of a usability evaluation. A study has shown that test reports are very common and standardized documents [5]. Muller \& Czerwinski [19] also describe the use of reports within Microsoft to share findings and usability engineers' recommendations, by making them available on the company intranet.

When feedback is based on a report, the literature provides some guidance on the structure and contents of that document. A few authors present specific advice on the structure and content of a usability report. The advices presented in Sy [31] are: include the goals of the test, order usability problems according to how critical they are and use bulleted lists, tables, and graphical presentation for quick retrieval of information. Redish et al. [26] and Perfetti [24] mention the following advice: the report should not be too long, present a manageable number of problems, include an executive summary, include severity classifications, include the number of users, who experienced the problem, and include positive findings.

Formalized forms of feedback like the report emphasize the relationship between evaluators and designers. Receiving feedback which describes problems in a system that the designers have personal involvement in, can be a discouraging task. When usability issues in a design are pointed out as being problematic, the designers will 
sometimes make an effort to defend the design, described as 'design defensiveness' [30]. These problems are often caused by the lack of basic understanding about what usability really is [15:414]. This prompts for the need to investigate the communicative mechanisms at play, when this form of feedback is provided to designers.

\section{Experimental Design}

In this section we present our experiment. The focus is on the experimental procedure and the structure of the usability reports that were the foundation of the experiment.

\subsection{Participants and System}

Our experiment involved two groups: designers and evaluators. For the experiment to be as realistic as possible, we collaborated with developers from a software company, who were working on the development of a mobile system. We could involve two developers from the company in the experiment. They were responsible for the design of the user interface of the system we evaluated. They described themselves as experienced interface designers based on their educational background and their work.

The system that was evaluated is a system that is used for registering use of time, materials, mileage, and equipment and for providing online access to the inventory, while working in the field. The system runs on a regular mobile phone with a barcode scanner attached. Most of the registrations and interactions with the system are based on barcodes that are taken from a small book. The target user group is for example servicing engineers, home-helpers, carriers, crafts- and workmen.

Table 1. The structure of the usability reports. Bold numbers denotes chapters and letters sections.

\begin{tabular}{|lll|}
\hline \multicolumn{1}{|c|}{ Usability report structure } & \\
\hline 1. Summary & 3. Results & 4. Conclusion \\
2. Method & a) Workload (NASA-TLX) & 5. Appendix \\
a) Purpose & b) Time used & a) Tasks \\
b) Procedure & c) Problem overview & b) Interview guide \\
c) Test participants & d) Detailed description of problems & c) Questionnaires \\
d) Test procedure & & d) Video log-files \\
e) Location \& equipment & & e) System log-files \\
f) Identification \& categorization of problems & & f) Task solutions \\
\hline
\end{tabular}

\subsection{The User-Based Usability Evaluation}

The purpose of the experiment was to examine how usability reports could change the developers' opinions about the major challenges and advantages of the system. The basis was two usability reports that were made as part of a related experiment.

The two usability reports were from two different usability evaluations of the mobile system described above. One of the evaluations was conducted in a state-of-theart usability laboratory at Aalborg University and the other in a field setting at Vitus Bering CEU (technical high school) in Horsens. Yet the fact that the two reports were from evaluations in different settings is not important for this experiment. 
Usability reports are often very extensive, take a long time to produce, and involve a heavy workload for the author [5]. Therefore, it is paramount that the feedback designers receive from such reports are useful. Otherwise, producing the report would be a waste of resources. The structure of our usability reports are illustrated in Table 1. Apart from minor adjustments, this structure is based on Rubin's [28:288-293] description on how to structure a usability report. The enumeration in this structure will be used as a reference later on in this paper, where the developers' opinion on what parts of the report they found the most important is presented.

\subsection{Data Analysis and Problem Descriptions}

The two usability evaluations were conducted by two different teams of two persons. The entire process of analyzing the data and writing the reports were done by the same persons that conducted the test. The two teams were not allowed to discuss any results or findings before the entire process was complete. In advance, a common severity rating procedure was agreed upon, which was based on three ratings proposed in Molich [17]. Table 2 shows the number of usability problems documented, described and rated according to severity in the reports.

Table 2. Number of usability problems found in both evaluations according to severity

\begin{tabular}{|l|r|r|}
\hline & Field & Laboratory \\
\hline Critical & 15 & 14 \\
\hline Severe & 16 & 14 \\
\hline Cosmetic & 17 & 6 \\
\hline Total & $\mathbf{4 8}$ & $\mathbf{3 4}$ \\
\hline
\end{tabular}

As the table illustrates, the number of critical and severe problems found is almost identical in the two evaluations. A more through comparison of the results can be found in [22].

\subsection{Developer Opinions}

Table 3 shows the 5 steps of the experiment and the involvement of the two developers. In the first step, they were asked to write down their initial understanding of usability and usability evaluation. In addition, their expectations to the usability reports were uncovered. Following this, they were interviewed about their initial opinion on strengths and weaknesses in the system (step 2). Then they were presented with the two usability reports one and a time and in opposite order. The task of describing and explaining strengths and weaknesses in the system was repeated after each of the reports had been read. Each time strengths and weaknesses had been identified, the developer was also asked to rank them relative to each other.

The usability reports from the two evaluations were presented to each developer in opposite order (step $3+4)$ to see if the order in which they were read would influence how the developers perceived them. The developers were kept separate until they made the final common list. This list (step 5) was compiled by the two developers in cooperation. First the final list from each developer was written on a white-board 
without ratings. Then the developers were asked to discuss and finally agree on a rating for all of the items of the two lists. The rating was important, but it also served the purpose of forcing the developers to discuss and reflect on each item.

Table 3. An overview of the structure of the experiment

\begin{tabular}{|l|l|l|}
\hline Step & Developer A & Developer B \\
\hline$\# 1$ & Outline the process for the developers, without revealing details. \\
\hline \multirow{2}{*2}{} & $\begin{array}{l}\text { Semi-structured interview on initial opinions on } \\
\text { advantages and disadvantages }\end{array}$ & $\begin{array}{l}\text { Semi-structured interview on initial opinions on } \\
\text { advantages and disadvantages }\end{array}$ \\
\hline \multirow{2}{*3}{} & $\begin{array}{l}\text { Recieve and read the laboratory usability } \\
\text { report. Semi.structured interview based on } \\
\text { step \#2. Interview is conducted by one of the } \\
\text { writers of the laboratory report. }\end{array}$ & $\begin{array}{l}\text { Recieve and read the field usability report. } \\
\text { Semi.structured interview based on step \#2. } \\
\text { Interview is conducted by one of the writers of } \\
\text { the field report. }\end{array}$ \\
\hline \multirow{3}{*}{ \#4 } & $\begin{array}{l}\text { Recieve and read the field report. } \\
\text { Semi.structured interview based on step \#3. } \\
\text { The developer is asked to comment on the } \\
\text { usefulness of the reports and the individual } \\
\text { parts. Interview is conducted by one of the } \\
\text { writers of the field report. }\end{array}$ & $\begin{array}{l}\text { Recieve and read the laboratory report. } \\
\text { Semi.structured interview based on step \#3. } \\
\text { The developer is asked to comment on the } \\
\text { usefulness of the reports and the individual } \\
\text { parts. Interview is conducted by one of the } \\
\text { writers of the laboratory report. }\end{array}$ \\
\hline $\begin{array}{l}\text { Group discussion where the developers are presented with each others list of advantages and } \\
\text { disadvantages. The two developers are asked to agree on a joint list. }\end{array}$ \\
\hline
\end{tabular}

\subsection{Conducting and Analysing the Interviews}

The developers were interviewed when they made the lists with strengths and weaknesses. Our approach was a semi-structured interview, also known as a qualitative research interview [13]. In this type of interview the interviewer starts out with the most general questions in order to gain some initial knowledge concerning the interviewee. He then moves on to ask follow-up questions, which leads on to specific questions on specific topics. Based on the answers from the interviewee, the interviewer finishes of by asking questions, which indirectly aim at interpreting the statements made.

To analyze the interviews, we used opinion condensation as described by Kvale [13:186-206]. This was done two days after the interviews. Through this kind of transcription, opinions expressed by the interviewees are transformed into shorter and more precise formulations. The intention of the condensation is to be as precise as possible, which means that we maintain the keywords that the interviewee use. Longer pieces of speech are condensed into a single or few sentences. The advantage of opinion condensation is that is can help present a relatively large amount of empirical data in an easy-to-read fashion, while both preserving and clarifying important issues. Opinion condensation can never be considered equal to 'traditional' transcription of the interview, which has significantly higher level of detail and involves less processing of the original text (audio recordings).

\section{Results}

This section presents the key findings from the experiment. When referring to sections in the usability reports notations like '(3a)' are used, which refers to the section 
on workload in Table 1. Steps in the experiment are referred to by '(step x)'. Quotes from the interviews are in 'italics'.

\subsection{The Concept of Usability}

Before reading the usability reports both developers were asked to express how they understood the term usability. Both of them were able to formulate this in specific terms. Developer A found that 'intuitive' is the word that described it best, but also mentioned 'easy' and 'straightforward' to use, without having to read several manuals. Developer B defined usability as the specific screens in the system, where the design of the screens should target the user and the information presented should be relevant. Additionally, the user interface should be easily understood and nice to look at. The developers stated that usability is and always has been important in their daily work, but that time issues prevent them from analysing and considering different ideas.

Table 4. The problem lists that developer A generated

\begin{tabular}{|c|c|c|}
\hline \multirow[b]{2}{*}{ List } & \multicolumn{2}{|r|}{ Developer A } \\
\hline & Advantages & Disadvantage \\
\hline $\begin{array}{l}\text { \#1 } \\
\text { Before } \\
\text { Reading } \\
\text { Reports }\end{array}$ & $\begin{array}{l}\text { 1. Online: The system can provide } \\
\text { relevant real time information. } \\
\text { 2. Barcode scanners: All interaction } \\
\text { begins with the user scanning. } \\
\text { 3. No software on the mobile } \\
\text { phone. }\end{array}$ & $\begin{array}{l}\text { 1. GPRS: Limited coverage. } \\
\text { 2. Barcodes are used to interact with the system } \\
\text { instead of the mobile phone. } \\
\text { 3. Online: problem when no connection is available. }\end{array}$ \\
\hline $\begin{array}{l}\text { \#2 } \\
\text { After } \\
\text { First } \\
\text { Report }\end{array}$ & $\begin{array}{l}\text { 1. Online / No software on mobile } \\
\text { phone. } \\
\text { 2. The use of barcode technology. } \\
\text { 3. Customizable. }\end{array}$ & $\begin{array}{l}\text { 1. No manual or documentation. } \\
\text { 2. Error messages. } \\
\text { 3. Handling of logical errors. } \\
\text { 4. Input of data through the mobile phone is problem- } \\
\text { atic in relation to target user group. } \\
\text { 5. Human resistance towards the system. }\end{array}$ \\
\hline $\begin{array}{l}\text { \#3 } \\
\text { After } \\
\text { Second } \\
\text { Report }\end{array}$ & $\begin{array}{l}\text { 1. Online / No software on mobile } \\
\text { phone. } \\
\text { 2. Customizable. } \\
\text { 3. The use of barcode technology. } \\
\text { 4. Hardware: mobile phone. Every- } \\
\text { body knows it. }\end{array}$ & $\begin{array}{l}\text { 1. Human resistance towards the system. Employees } \\
\text { feel that they are under surveillance. } \\
\text { 2. No manual or documentation. } \\
\text { 3. Many barcodes needed to navigate the system. } \\
\text { 4. Browser technology/phone restrictions: Input of } \\
\text { data through the mobile phone is problematic in } \\
\text { relation to target user group. } \\
\text { 5. Error messages and handling of logical errors. }\end{array}$ \\
\hline
\end{tabular}

\subsection{Developers' View on System Advantages and Disadvantages}

Developer A had, especially in the beginning, some difficulties in naming five advantages and disadvantages in the system and actually never succeeded in mentioning five, see Table 4. He was also somewhat reluctant in prioritizing the items in the lists His advantages reflected the arguments that the system was sold upon, whereas the disadvantages reflected the technical issues encountered in the development process.

After reading the first report, developer A did not change his list of advantages noticeable; the points were merely rephrased. On the contrary his list of disadvantages was completely altered as he adapted many of the issues described in the usability 
report and was able to expand the list to five items and more reflected issues that concerned interaction with the system. Furthermore social implications caused by the usage of the system became evident to the developer.

The second usability report did not have a profound influence on his belief about strength in the system. It made him rearrange two subjects, but also ad the use of daily technology as an advantage. Regarding disadvantages reading the report made him rearrange the rankings in the list and expand and rephrase the descriptions of two subjects.

Table 5. The problem lists generated by developer B

\begin{tabular}{|c|c|c|}
\hline \multirow[b]{2}{*}{ List } & \multicolumn{2}{|c|}{ Developer B } \\
\hline & Advantages & Disadvantage \\
\hline $\begin{array}{l}\# 1 \\
\text { Before } \\
\text { Reading } \\
\text { Reports }\end{array}$ & $\begin{array}{l}\text { 1. Hardware: mobile phone. } \\
\text { 2. Few scans necessary. } \\
\text { 3. Customizable. } \\
\text { 4. Online - real time. } \\
\text { 5. Simple solution with limited interaction. }\end{array}$ & $\begin{array}{l}\text { 1. Screen size } \\
\text { 2. Problems with GPRS. Often slow. } \\
\text { 3. No manual or documentation. } \\
\text { 4. Only works on some types of mobile phones. }\end{array}$ \\
\hline $\begin{array}{l}\text { \#2 } \\
\text { After } \\
\text { First } \\
\text { Report }\end{array}$ & $\begin{array}{l}\text { 1. Hardware: mobile phone. Everybody is } \\
\text { familiar with the technology. } \\
\text { 2. Displays only necessary information. } \\
\text { 3. Customizable. } \\
\text { 4. Online all the time. } \\
\text { 5. The system is simple and uniform. }\end{array}$ & $\begin{array}{l}\text { 1. The text describing each of the barcodes. } \\
\text { 2. More user education in needed. } \\
\text { 3. System reply time. } \\
\text { 4. Screen size. Difficult to maintain an overview. } \\
\text { 5. System is interpreted differently on different } \\
\text { phones. }\end{array}$ \\
\hline $\begin{array}{l}\text { \#3 } \\
\text { After } \\
\text { Second } \\
\text { Report }\end{array}$ & $\begin{array}{l}\text { 1. Hardware: mobile phone. Everybody } \\
\text { knows it. } \\
\text { 2. The system is simple and uniform. } \\
\text { 3. Customizable. } \\
\text { 4. Displays only necessary information. } \\
\text { 5. Online all the time. }\end{array}$ & $\begin{array}{l}\text { 1. The text describing each of the barcodes. } \\
\text { 2. More user education in needed. } \\
\text { 3. System reply time. } \\
\text { 4. Screen size. Difficult to maintain an overview. } \\
\text { 5. System is interpreted differently on different } \\
\text { phones. }\end{array}$ \\
\hline
\end{tabular}

Unlike his colleague, developer B was from the beginning able to list five subjects in the list of advantages and four in disadvantages. Most of his initial subjects were kept through the entire process and was only slightly altered and rearranged, as seen in Table 5.

After reading the first report the description of the highest ranking advantage was elaborated and the second highest subject was replaced. His list of disadvantages on the other hand was expanded with a problem of understanding the possibilities of interaction as a new highest ranking problem. The remaining subjects were rephrased and rearranged. Reading the second usability report did not influence developer B enough to make noticeable changes. Only alterations to advantage list the description and ranking of the two last subjects were made.

The elaboration of the joint list, depicted in Table 6, included both developers and gave rise to discussion between the two, where especially the ranking process served as fuel for the fire. The developers discussed each subject on their lists until an agreement was reached. It is noticeable that all the advantages in the final list can be back traced to the developers' initial lists, either in one or both lists. Some subjects have been rephrased but depict in general the same advantage. The story is different when it comes to the disadvantages. Here the two top subject also originates from 
both developers initial lists, but the third subject is A's final top disadvantage. The two last subjects are derived from developer B's final list and are subjects that were added to list in the experimental process.

Table 6. The joint problem list, which was made in cooperation between both developers

\begin{tabular}{|c|c|c|}
\hline \multirow{7}{*}{$\begin{array}{l}\text { List } \\
\# 4 \\
\text { After } \\
\text { Group } \\
\text { Interview }\end{array}$} & \multicolumn{2}{|c|}{ Joint List - Developer A \& B } \\
\hline & Advantages & Disadvantages \\
\hline & 1. Online - real time. & 1. Online: Problems with GPRS. \\
\hline & 2. Customizable. & 2. No manual or documentation. \\
\hline & $\begin{array}{l}\text { 3. Rely on commonly known technology: } \\
\text { mobile phone. }\end{array}$ & $\begin{array}{l}\text { 3. Human resistance towards the system. } \\
\text { Employees feel that they are under surveil- } \\
\text { lance. }\end{array}$ \\
\hline & 4. Simple and small barcode-scanner. & 4. More user education in needed. \\
\hline & 5. The system is simple and uniform. & $\begin{array}{l}\text { 5. Error messages and handling of logical } \\
\text { errors. }\end{array}$ \\
\hline
\end{tabular}

\subsection{Usefulness of the Reports}

Regarding the reports both developers used the same approach when reading them. Basically the reports were read from the beginning to the end. Occasionally the appendices (5) were used to see the design of the tasks. The log-files $(5 d+5 e)$ were not read in their entirety, but were used to examine details concerning a problem, if they were uncertain why a problem had occurred. Developer B stated when asked: 'I used the log-files to gain further insight into what happened'.

Both developer A and B mentioned that the overview of the usability problems (3c) and the elaborating descriptions (3d) were important in the future work on the system: 'I really like the problem list and it is something I can use concretely in my work'. The log-files (5d) were good, because 'they describe what they (the test participants) did. It provided a better feel of what they did, why they could not figure it out, and what they did next'. This shows that log-files are useful, for providing further insight when trying to understand some of the problems in detail.

Log-files can provide almost firsthand insight into what specific actions the user performed. Although they cannot be used directly to resolve the problems, the developers find them important to understand the conditions under which the tests have been conducted (2). This was mentioned by both developers as being very important in respect to how they rate the validity of the evaluation. On the contrary, developer B mentions that: 'The other assessments and similar are quite fun to read, but they are not very useful', referring to the summary (1) and the conclusion (4). It is important to note that executive summaries may still be important in a more general organizational context.

The developers found the NASA-TLX (3a) method interesting, but they experienced some problems in interpreting tables displaying NASA-TLX results. Developer $\mathrm{B}$ found that one of the usability reports, the one based on the field evaluation, lacked a transcription of the debriefing conducted at the end of each test. This was important, since: 'It would provide me with a better insight into the participants' attitude towards the system'.

During the final interview (step 5), the developers brought up the issue of using video recordings. In relation to some of the problems encountered in: 'the first few minutes, when the user for the first time was presented with the mobile phone', it 
would have been beneficial if the video material had been available. This would have given him a chance to see the test participants' first reactions.

When asked, which of the two reports, they found to be the best, they both replied that it was the one they read as the first one. Developer B said that the laboratorybased report was the best because transcriptions of the debriefing following each test were available in the $\log (5 \mathrm{~d})$. He also mentions that: 'it reflects the reality I know best' and that the field report appears more 'critical'. Developer A found the field based report to be the best, as he found that it was more detailed in it descriptions of the problems (3d).

\subsection{Social and Organizational Aspects}

Limited time is an overall issue throughout the interviews and in several occasions the two developers use this as an excuse for some of the existing usability problems. In the beginning, before having seen any of the reports (step 2), developer A said: 'We know that many of the things are there - many things that we would really like to correct if we had the time'. Numerous times both developers mentioned that designing the user interface is an important and necessary part of their job, but that they cannot spend much time on analyzing and considering different ideas. They are simply too busy and therefore have not got the necessary time. Developer A expressed that this should be taken into account when evaluating the usability of a system.

As developers, they often find themselves thinking in 'states' and 'actions', but according to both developers, the reports can help them to gain further insight into how the users think, when they use the system.

\subsection{Evaluation Setup}

One of the issues frequently referred to during the interviews was that the users were very inexperienced, and if they were more experienced, the result of the evaluation would have been different. This is probably correct, but it does not imply that usability problems found by relatively inexperienced users do not exist. We see this more as a defensive reaction towards, a perhaps, overwhelming number of usability problems seen from the developers point of view. This is supported by the developers accepting that many of the problems were relevant and should be fixed. When developer A was asked about his general opinion on the evaluations, he replied that: 'Many of the things mentioned have applicability in our further work' and added that he: 'can relate to the findings and use them positively'.

Another point of critique presented by the developers was that the tasks were not realistic and that this might have affected the outcome of the tests. According to Molich [18] this is a typical objection raised by developers. Still developer A mentioned: 'I am impressed with how many strange errors the users manage to provoke, which we have never thought of ourselves'.

\section{Discussion}

Before reading any of the usability reports developer B expressed that he had great expectations to the usability evaluation. However, he was somewhat worried that we 
as evaluators might not have had enough experience in using the system, whereas a potential user has a need for doing the things that the system can. He thought the evaluation might have had another outcome, if we had done the evaluation one more time. We find this as an example of the developer being defensive [30].

Developer A expressed that the time pressure, they work with every day, should be taken into account when evaluating the usability of the system. In relation to usability evaluations this makes little sense. Usability problems exist in a system regardless of the time that has been available for development. The issue of designers being reluctant to allocate time in their schedule for HCI activities has been described before, for example by Radle \& Young [25] and Spencer [30].

Regarding the structure and content of usability reports, a question about whether to include an edited videotape as part of the feedback for the designers, to allow designers a first hand view of the problem, arose. This has been tried at IBM [9]. Traditional reports are still utilised, but video clips can 'provide compelling evidence to developers who are reluctant to correct usability problems' [9]. A drawback associated with the use of video recordings is that it is very time-consuming task to edit such a tape [5].

Very few positive findings were presented in the two reports. When the developers were asked, whether they would have liked the evaluation to focus more on positive findings, they replied that positive findings are always nice, but they cannot really use them for improving the system. Hence they do not find any reason for spending a lot of time and energy on finding positive aspects. Both Perfetti [24] and Redish et al. [26] support the idea of including positive findings in usability reports. Frøkjær and Hornbæk [11] on the other hand report from a series of interviews where practitioners criticized the form of traditional usability reports, that developers were much more interested in constructive proposals for redesign.

Alternative approaches to usability reports as a mean for providing feedback have been proposed. This experiment has actively included the developers in generating an additional usability problem list, hereby succeeding in forcing the developers to take a stand towards the usability problems presented to them. Redish et al. [26] takes the cooperation with the designers a step further by suggesting that they are brought in and made a part of the planning and conducting of the evaluation, analysis of the data, and the communication of the results.

Moving feedback from the written to spoken language changes the criteria for giving good feedback. Radle \& Young [25] recognize the importance of interpersonal skills when addressing usability in relation to development teams. Sy [31] also presents additional advises on how communication of the evaluation results can be improved apart from a usability report. If possible, a meeting should be held to go through the findings with the appropriate people. During this meeting, it is important to refrain from any kind of confrontational attitude, and if possible, the meeting should be ended with a list of actions derived from a co-operative discussion. This is important in order to involve designers more actively in the resolution of usability problems

\section{Conclusion}

Through the experiment we have learned a number of lessons, which are relevant in providing feedback to designers through usability reports and interviews about usability problems. This leads us to conclude that: 
- A problem list providing overview of usability problems combined with detailed descriptions is important in a report and essential for the designers when trying to understand a problem.

- Results of NASA-TLX, which are not explained and put into context, are difficult for the designers to relate to.

- Log-files of user interaction, based on video recordings combined with systemlogs, are used and considered important by the developers to understand specific details of the usability problems.

- Information on test setup, users, tasks, and test users' subjective opinions are important to the developers, but these are also the point of critique, when developers explain, why they find problems more or less real.

- General assessments and evaluations in usability reports have limited usefulness for the designers.

The reports were useful for the designers in understanding the usability evaluation and as a mean for references in redesign and further development. They enriched the developers with insight into how users interact with their product and what strengths and weaknesses there were. For the developers the usability reports did not alter their initial belief of the system to a great extent, but it did expand their list and made them consider other topics. The reports had a more substantial effect on the developers' conception of the weaknesses of the system.

In this experiment, we rely heavily on qualitative data collected through interviews with two participants. In addition, the two developers can in no way be representative for all user interface designers.

Based on the results of our experiment, we find that it would be interesting to perform similar feedback experiments with other ways of providing feedback to designers. Inspiration can be found in the area of interpersonal communication. The other important avenue of research is to conduct similar experiments with other designers to broaden the empirical basis for more general conclusions.

\section{References}

1. Bachrach, C. \& Newcomer, S. F. (2002). Addressing Bias in Intervention Research, in Journal of Adolescent Health, Volume 31, Number 4, 2002.

2. Bærentsen, K. B. \& Slavensky, H. (1999). A Contribution to the Design Process. Communications of the ACM, May 1999, Vol. 42, No. 5.

3. Baillie, L. (2003). Future Telecommunication: Exploring actual use, INTERACT 2003.

4. Blatt, L., Jacobsen, M. \& Miller, S. (1994). Designing and equipping a usability laboratory, In BIT Volume 13, Numbers 1 \& 2, January -April 1994, Special Issue 'Usability Laboratories'

5. Borgholm, T. \& Madsen, K. H. (1999). Cooperative Usability Practices. Communications of the ACM, May 1999, Vol. 42, No. 5.

6. Dolan, W. R. \& Dumas, J. S. (1999). A Flexible Approach to Third-Party Usability. Communications of the ACM, May 1999, Vol. 42, No. 5.

7. Dumas, J. S. \& Redish, J. C. (1993). A practical guide to usability testing, Norwood, NJ: Ablex Publishing. 
8. Ehrlich, K., Beth, M. B. \& Pernice, K. (1994). Getting the Whole Team into Usability Testing, IEEE Interface - January 1994.

9. Fath, J. L., Teresa, L. M. \& Holzman, T. G. (1994). A practical guide to using software usability labs: lessons learned at IBM, In BIT Volume 13, Numbers 1 \& 2, January -April 1994, Special Issue 'Usability Laboratories'

10. Fowler, C., Stuart, J., Lo, T. \& Tate, M. (1994). Using the usability laboratory: BT's experiences, In BIT Volume 13, Numbers 1 \& 2, January -April 1994, Special Issue 'Usability Laboratories'

11. Frøkjær, E. and Hornbæk, K. (2004) Input from usability evaluation in the form of problems and redesigns: results from interviews with developers. In Hornbæk, K. and Stage, J. (Eds.) Proceedings of the Workshop on Improving the Interplay between Usability Evaluation and User Interface Design, NordiCHI 2004, pp. 27-30. Aalborg University, Department of Computer Science, HCI-Lab Report no. 2004/2.

12. Hartson, H. R., Shivakumar, P. \& Pérez-Quiñones, M. A. (2004). Usability Inspection of Digital Libraries: A Case Study, accepted for publication in the Special Issue of Journal of Digital Libraries on Usability

13. Kvale, S. (1997). Interview - En Introduction til det Kvalitative Forskningsinterview, Hans Reitzels Forlag, 1. udgave, 1997.

14. Lund, A. M. (1994). Ameritech's usability laboratory: from prototype to final design, In BIT Volume 13, Numbers 1 \& 2, January -April 1994, Special Issue 'Usability Laboratories'

15. Mayhew, D. J. (1999). The Usability Engineering Lifecycle, Morgan Kaufmann Publishers Inc. San Francisco, California.

16. Mayhew, D. J. (1999). Strategic Development of the Usability Engineering Function, ACM Transactions - September /October 1999.

17. Molich, R. (2000). Brugervenlige edb-systemer, Teknisk Forlag.

18. Molich, R. (2004). E-mail correspondence with Rolf Molich 18/05/04.

19. Muller, M. J. \& Czerwinski, M. (1999). Organizing Usability Work To Fit the Full Product Range. Communications of the ACM, May 1999, Vol. 42, No. 5.

20. Murphy, J., Howard, S., Kjeldskov, J. and Goschnick, S. (2004) Location, Location, Location: Challenges of Outsourced Usability Evaluation. In Hornbæk, K. and Stage, J. (Eds.) Proceedings of the Workshop on Improving the Interplay between Usability Evaluation and User Interface Design, NordiCHI 2004, pp. 12-15. Aalborg University, Department of Computer Science, HCI-Lab Report no. 2004/2.

21. Nielsen, M. C., Overgaard, M., Pedersen, M. B. \& Stenild, S. (2004). A Review of Literature on Usability Evaluation Methods for Mobile Systems, Department of Computer Science, Aalborg University, 2004.

22. Nielsen, M. C., Overgaard, M., Pedersen, M. B. \& Stenild, S. (2004). Usability Evaluation of a mobile system: Comparison of a Laboratory and Field Evaluation, Department of Computer Science, Aalborg University, 2004.

23. Palmiter, S., Lynch, G., Lewis, S. \& Stempski, M. (1994). Breaking away from the conventional 'usability lab': the Customer-Centered Design Group at Tektronix, Inc., In BIT Volume 13, Numbers 1 \& 2, January -April 1994, Special Issue 'Usability Laboratories'

24. Perfetti, C. (2003). Usability Testing Best Practices: An Interview with Rolf Molich. Originally published: 07/24/2003, Found 10/05/04: http://www.uie.com/articles/ molich_interview.

25. Radle, K. \& Young, S. (2001). Partnering Usability with Development: How Three Organizations Succeeded, IEEE Software - January/February 2001. 
26. Redish, J., Bias, R. G., Bailey, R., Molich, R., Dumas, J. \& Spool, J. M. (2002). Usability in Practice: Formative Usability Evaluations - Evolution and Revolution. Usability in Practice Session, CHI 2002.

27. Rohn, A. J. (1994). The usability engineering laboratories at Sun Microsystems, In BIT Volume 13, Numbers 1 \& 2, January -April 1994, Special Issue 'Usability Laboratories'

28. Rubin, J. (1994). Handbook of usability testing: How to plan, design, and conduct effective tests, New York, NY: John Wiley \& Sons.

29. Salzman, M. C. \& Rivers, S. D. (1994). Smoke and mirrors: setting the stage for a successful usability test, In BIT Volume 13, Numbers 1 \& 2, January -April 1994, Special Issue 'Usability Laboratories'

30. Spencer, R. (2000). The Streamlined Cognitive Walkthrough Method, Working Around Social Constraints Encountered in a Software Development Company, CHI Letter 2000 Volume 2 Issue 1.

31. Sy, D. (1994). Bridging the Communication Gap in the Workplace With Usability Engineering, ACM 1994.

32. Zirkler, D. \& Ballman, D. R. (1994). Usability testing in a competitive market: lessons learned, In BIT Volume 13, Numbers 1 \& 2, January -April 1994, Special Issue 'Usability Laboratories' 